\title{
Persistence and adherence with the new beta-3 receptor agonist, mirabegron, versus antimuscarinics in overactive bladder: Early experience in Canada
}

\author{
Adrian Wagg, MD; ${ }^{*}$ Billy Franks, PhD; Barbara Ramos, PhD; Todd Berner, MD走 \\ *Department of Medicine, University of Alberta, BC; ${ }^{*}$ Astellas Pharma Canada Inc., Markham, ON; §Astellas Scientific and Medical Affairs, Northbrook, Ll; ${ }^{\star}$ Astellas Scientific and Medical Affairs, Northbrook, IL
}

See related commentary on page 351.

Cite as: Can Urol Assoc J 2015;9(9-10):343-50. http://dx.doi.org/10.5489/cuaj.3098 Published online October 13, 2015.

\begin{abstract}
Introduction: Antimuscarinics are the principal pharmacological treatment for overactive bladder $(\mathrm{OAB})$, but frequently give rise to anticholinergic side effects, such as dry mouth, a factor leading to poor persistence. The $\beta_{3}$-adrenoceptor agonist mirabegron is devoid of significant anticholinergic activity, while being effective in OAB. We evaluated persistence and adherence with mirabegron versus antimuscarinics over 12 months.

Methods: We obtained retrospective claims from a Canadian Private Drug Plan database for patients 18 years old and over, with a first claim for mirabegron or antimuscarinics during a 6-month index period (April-September 2013). A 6-month look-back identified those with no prior claims for OAB medication (treatmentnaïve) or $\geq 1$ prior $O A B$ drug (treatment-experienced). Time to end of persistence ( $\geq 30$ day therapy gap or switch of therapy) was evaluated over 12 months; adherence with medication (medication possession ratio) was also measured.

Results: Persistence data from 19485 patients (74\% female, $92 \%$ naïve, $19.9 \%$ aged $\geq 65$ years) showed that for experienced patients the median number of days on mirabegron was 299 days, compared with a range of 96 to 242 days for the different antimuscarinics; for naïve patients, it was 196 versus 70 to 100 days, respectively. Persistence at 12 months was for mirabegron $39 \%$ versus $14 \%$ to $35 \%$ for antimuscarinics, (experienced) and $30 \%$ mirabegron versus $14 \%$ to $21 \%$ antimuscarinics, (naïve). Patients taking mirabegron demonstrated statistically significantly greater adherence than those taking antimuscarinics.

Conclusion: Patients who received mirabegron remained longer on treatment than those treated with antimuscarinics, and had higher 12-month persistence and adherence rates.
\end{abstract}

\section{Introduction}

Overactive bladder $(\mathrm{OAB})$ is a chronic, age-related disorder occurring in more than 1 in 7 women and men. ${ }^{1,2}$ The symptoms of urinary urgency, with or without urinary incontinence, increased daytime frequency and nocturia, ${ }^{3}$ together with various comorbidities, ${ }^{4,5}$ can have a devastating effect on quality of life. ${ }^{6}$

The principal drugs used for $O A B$ are antimuscarinic agents. Unfortunately there is a high rate of discontinuation from these drugs, ${ }^{7-13}$ with up to $86 \%$ of patients in a UK study stopping therapy after 1 year. ${ }^{12}$ In a Canadian study of 31754 patients with OAB who were treated with antimuscarinics, about $91 \%$ discontinued within a 4-year follow-up, and most did not have second-line treatment. ${ }^{14}$

Although there could be several reasons for discontinuation, a high incidence of anticholinergic adverse events, such as dry mouth and constipation, is likely to play a role. For example, a Canadian study reported that $83 \%$ of patients with $\mathrm{OAB}$ experienced dry mouth when taking oxybutynin immediate release (IR) $5 \mathrm{mg}$ (the most widely used antimuscarinic); the side effect was graded severe in $28 \%$ of patients. ${ }^{15}$

Unlike antimuscarinic agents which act within the parasympathetic system, the recently introduced $\beta_{3}$-adrenoreceptor agonist mirabegron targets sympathetic stimulated relaxation of the bladder. ${ }^{16,17}$ This action improves the storage capacity of the bladder without inducing anticholinergic adverse events. A systematic review of 44 randomized controlled trials involving 27309 patients showed that mirabegron $50 \mathrm{mg}$ was as efficacious as antimuscarinics in reducing the frequency of micturition and incontinence, but had an incidence of dry mouth and constipation similar to placebo. ${ }^{18}$ In a 1-year study, mirabegron and tolterodine extended release (ER) $4 \mathrm{mg}$ were similarly effective, but mirabegron $50 \mathrm{mg}$ had a lower incidence of dry mouth $(2.8 \%$ vs. $8.6 \%) .{ }^{19}$ In a sub-analysis of patients aged $\geq 65$ 
Wagg et al.

years, the incidence of dry mouth after 1 year was 6-fold lower with mirabegron than with tolterodine ER. ${ }^{20}$

We report our early experience with mirabegron in Canada, using retrospective prescription claims data to compare persistence and adherence versus antimuscarinic drugs over 12 months.

\section{Methods}

Retrospective prescription claims were obtained from a Canadian National Private Drug Plan (PDP) database (IMS Brogan PDP, IMS Health Canada Inc., Kirkland, QC), which captures $68 \%$ of private claims and $86 \%$ of pay-direct private claims nationally. Prescriptions were tracked for the following target drugs: mirabegron, fesoterodine, oxybutynin $E R$, oxybutynin IR, solifenacin, and tolterodine ER.

Patients aged $\geq 18$ years who had a first prescription claim for a target medication during a 6-month index period from April to September 2013 were identified (Fig. 1). A 6-month look-back period prior to the patient's first claim (the index date) was used to categorize patients as treatment-naïve (no claims for a target $O A B$ medication) or treatmentexperienced ( $\geq 1$ prior $\mathrm{OAB}$ medication) during this time. Prescription claims for a target drug were tracked for 12 months after the index claim date to calculate time to end of persistence (defined by a gap in therapy of at least 30 days or switching to another medication), censored for patients who remained on initial therapy through to month 12 . Adherence (measured by medication possession ratio [MPR]) was calculated as the proportion of days the patient received the prescribed medication compared to their overall time on therapy (number of days supply, divided by the number of days in the follow-up period [365 days]; days supply beyond the observation window were not included).

Data were captured on treatment status (experienced or naïve), gender, age categories ( $<46$ years, $46-64$ years, $\geq 65$ years), index product, and the number of coexisting medications $(0,1-3,4-5,6-8,>8)$. Patients had to remain active in the drug plan during the full study period. Patients were

\begin{tabular}{|l|l|}
\hline $\begin{array}{l}\left.\text { SELECTION PERIOD (index date }=\mathrm{t}_{0}\right) \\
\text { (first fill-date for an OAB drug) }\end{array}$ \\
\hline $\begin{array}{l}\text { LOOK-BACK PERIOD } \\
\left(\mathrm{t}_{0}-6 \text { months) }\right.\end{array}$ & $\begin{array}{c}\text { ANALYSIS PERIOD } \\
\left(12 \text { months following } \mathrm{t}_{0}\right)\end{array}$ \\
$\begin{array}{l}\text { A look-back period of } 6 \text { months } \\
\text { prior to the patient's first claim } \\
\text { in the index period was used to } \\
\text { determine if the patient was } \\
\text { naïve to the target drugs and } \\
\text { active in the plan }\end{array}$ & $\begin{array}{l}\text { Each patient was observed } \\
\text { for } 12 \text { months after their } \\
\text { index date to calculate } \\
\text { persistence and adherence }\end{array}$ \\
\hline
\end{tabular}

Fig. 1. Study design. excluded if they had claims for 2 or more different $O A B$ products on the same day (i.e., data for combinations of mirabegron with antimuscarinics or the use of 2 or more different antimuscarinics were not captured).

Only anonymized patient-level data were used. No ethical committee review was required.

\section{Statistical analysis}

The total study cohort and separate cohorts of treatmentnaïve and treatment-experienced patients were analyzed using Cox proportional hazards modelling. This provided hazard ratios, 95\% confidence intervals (Cls) and $p$ values; $p$ value $<0.05$ was considered statistically significant. KaplanMeier survival curves were plotted to show persistence rates over time. Mean and median results were calculated for persistence, censored at 12 months after the first prescription. In the MPR analysis, $p$ values were determined by independent samples median test for equivalence. Pairwise comparisons were made with reference to the predetermined covariate using Mood's Median statistical test. The reference variables for hazard ratio calculations and MPR analysis are noted in the results tables. Data processing, summarization and analyses were performed using SAS Version 9.2 (SAS Institute, Inc., Cary, NC).

\begin{tabular}{|c|c|c|c|}
\hline & & No. patients & Percentage \\
\hline \multicolumn{4}{|c|}{ Therapeutic status* } \\
\hline & Naïve & 17890 & $91.8 \%$ \\
\hline & Experienced & 1595 & $8.2 \%$ \\
\hline \multirow[t]{2}{*}{ Gender } & Female & 14493 & $74.4 \%$ \\
\hline & Male & 4992 & $25.6 \%$ \\
\hline \multirow[t]{3}{*}{ Age (years) } & $\geq 65$ & 3875 & $19.9 \%$ \\
\hline & $46-64$ & 11276 & $57.9 \%$ \\
\hline & $<46$ & 4334 & $22.2 \%$ \\
\hline \multirow[t]{7}{*}{ OAB drug } & Mirabegron & 1683 & $8.6 \%$ \\
\hline & Solifenacin & 6032 & $31.0 \%$ \\
\hline & Oxybutynin IR & 5356 & $27.5 \%$ \\
\hline & Tolterodine ER & 3739 & $19.2 \%$ \\
\hline & Fesoterodine & 1415 & $7.3 \%$ \\
\hline & Oxybutynin ER & 1260 & $6.5 \%$ \\
\hline & 0 & 1157 & $5.9 \%$ \\
\hline \multirow{4}{*}{$\begin{array}{l}\text { No. coexistent } \\
\text { prescription } \\
\text { medications }\end{array}$} & $1-3$ & 7135 & $36.6 \%$ \\
\hline & $4-5$ & 4629 & $23.8 \%$ \\
\hline & $6-8$ & 4226 & $21.7 \%$ \\
\hline & $>8$ & 2338 & $12.0 \%$ \\
\hline
\end{tabular}




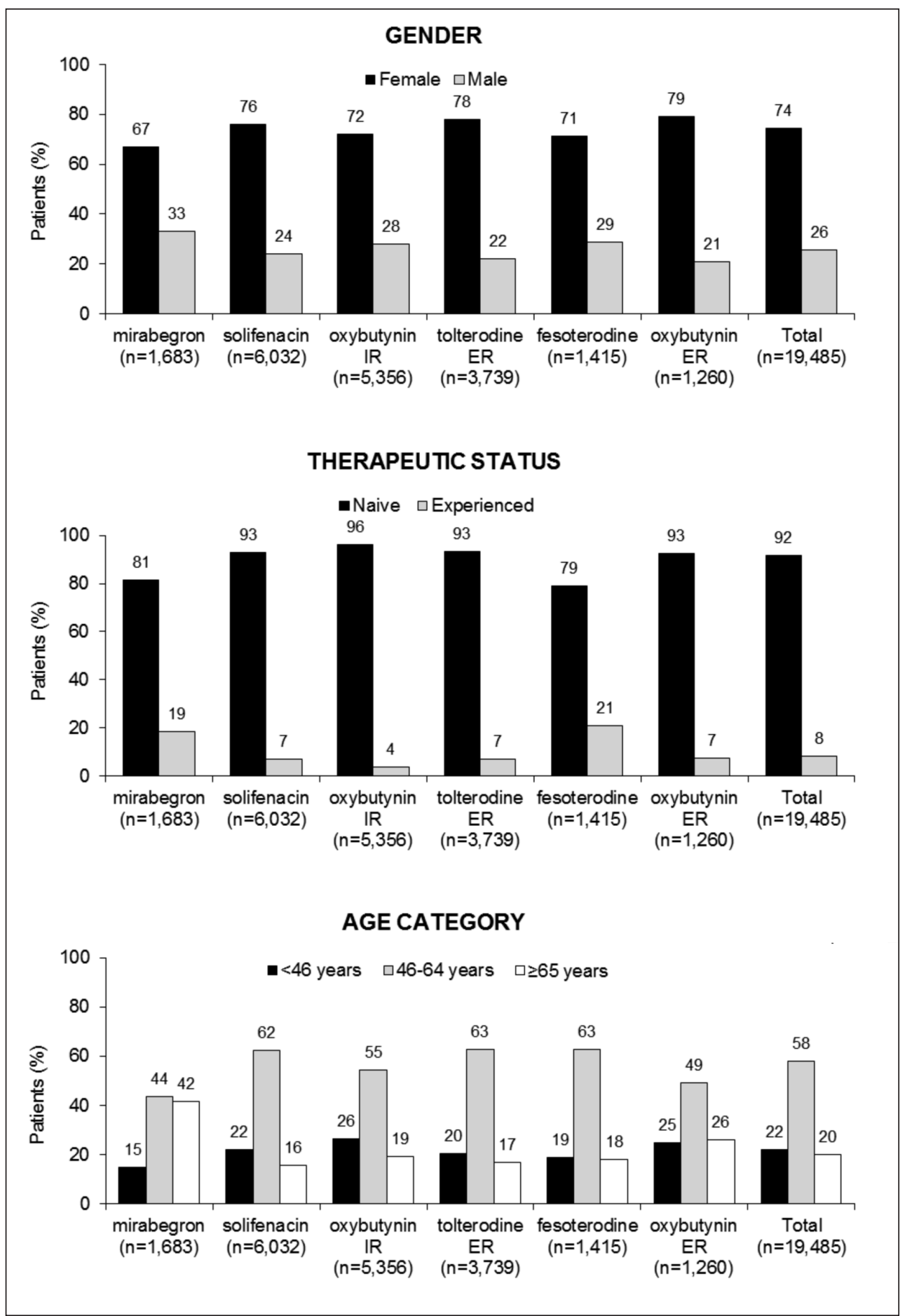

Fig. 2. Gender, therapeutic status and age group distribution for each drug.

\section{Results}

\section{Patient distribution}

The final cohort for the persistence and adherence analyses was 19485 patients. Compared with most of the other target therapies, a higher proportion of patients receiving mirabegron were male, treatment-experienced, and aged $\geq 65$ years (Fig. 2) (Table 1). 
Wagg et al.

\begin{tabular}{|c|c|c|c|c|}
\hline & No. patients & HR & $95 \% \mathrm{Cl}$ & $p$ value \\
\hline \multicolumn{5}{|l|}{ Status } \\
\hline Experienced* & 1595 & 1.000 & * & * \\
\hline Naïve & 17890 & 1.300 & $1.222-1.383$ & $<0.001$ \\
\hline \multicolumn{5}{|l|}{ Gender } \\
\hline Male* & 4992 & 1.000 & * & * \\
\hline Female & 14493 & 0.928 & $0.895-0.962$ & $<0.001$ \\
\hline \multicolumn{5}{|l|}{ Age (years) } \\
\hline$\geq 65^{*}$ & 3875 & 1.000 & * & * \\
\hline $46-64$ & 11276 & 1.029 & $0.986-1.073$ & 0.191 \\
\hline$<46$ & 4334 & 1.267 & $1.207-1.330$ & $<0.001$ \\
\hline \multicolumn{5}{|l|}{ OAB drug } \\
\hline Mirabegron* & 1683 & 1.000 & * & * \\
\hline Solifenacin & 6032 & 1.341 & $1.256-1.433$ & $<0.001$ \\
\hline Tolterodine ER & 3739 & 1.439 & $1.342-1.542$ & $<0.001$ \\
\hline Fesoterodine & 1415 & 1.446 & $1.342-1.542$ & $<0.001$ \\
\hline Oxybutynin ER & 1260 & 1.450 & $1.332-1.579$ & $<0.001$ \\
\hline Oxybutynin IR & 5356 & 1.807 & $1.691-1.931$ & $<0.001$ \\
\hline \multicolumn{5}{|c|}{ No. coexistent prescription medications ${ }^{\dagger}$} \\
\hline $0^{*}$ & 1157 & 1.000 & * & * \\
\hline $1-3$ & 7135 & 0.819 & $0.765-0.875$ & $<0.001$ \\
\hline $4-5$ & 4629 & 0.744 & $0.693-0.798$ & $<0.001$ \\
\hline $6-8$ & 4226 & 0.715 & $0.665-0.768$ & $<0.001$ \\
\hline$>8$ & 2338 & 0.668 & $0.618-0.723$ & $<0.001$ \\
\hline $\begin{array}{l}\text { Data from a single mu } \\
\text { variable, tFitted as a cl } \\
\text { overactive bladder; IR: }\end{array}$ & $\begin{array}{l}\text { ate model (Cox } \\
\text { ariable; HR: haze } \\
\text { diate release; E }\end{array}$ & $\begin{array}{l}\text { rtiona } \\
\text { tio; Cl: } \\
\text { tended }\end{array}$ & $\begin{array}{l}\text { ards model). *Re } \\
\text { fidence interval; } C \\
\text { ase. }\end{array}$ & \\
\hline
\end{tabular}

\section{Persistence: Total study population}

Statistically significant differences in the relative risk of discontinuation were found for each covariate group compared to the reference variable (Table 2).

Mirabegron was associated with the highest median number of days on therapy (221 days), whereas the lowest rate was seen with oxybutynin IR (75 days) (Fig. 3). Persistence at 12 months was greatest with mirabegron $(31.7 \%)$, and lowest with oxybutynin IR (13.8\%).

\section{Persistence: Treatment-naïve cohort}

Persistence at 12 months was $19.0 \%$ in treatment-naïve patients, compared with $30.0 \%$ in treatment-experienced patients. Mean (median) days on therapy was 159 (90) versus 207 (205) for naïve versus experienced patients, respectively.

Treatment-naïve patients taking mirabegron demonstrated statistically significantly greater persistence compared with those taking antimuscarinic drugs (Table 3, Fig. 4). Persistence at 12 months was $29.9 \%$ with mirabegron, compared with $13.8 \%$ to $21.0 \%$ with antimuscarinics. Lowest persistence was seen in patients taking oxybutynin IR, who were on average 1.8-times more likely to discontinue than those taking mirabegron. The mean (median) duration of treatment was 206 (196) days with mirabegron compared with 134 to 169 (range: 70-100) days with the different antimuscarinics.

Men were slightly more likely than women to discontinue treatment. Patients under 46 years of age were more likely to discontinue $\mathrm{OAB}$ treatment than those aged 65 years or older, but there was no significant difference in discontinu-

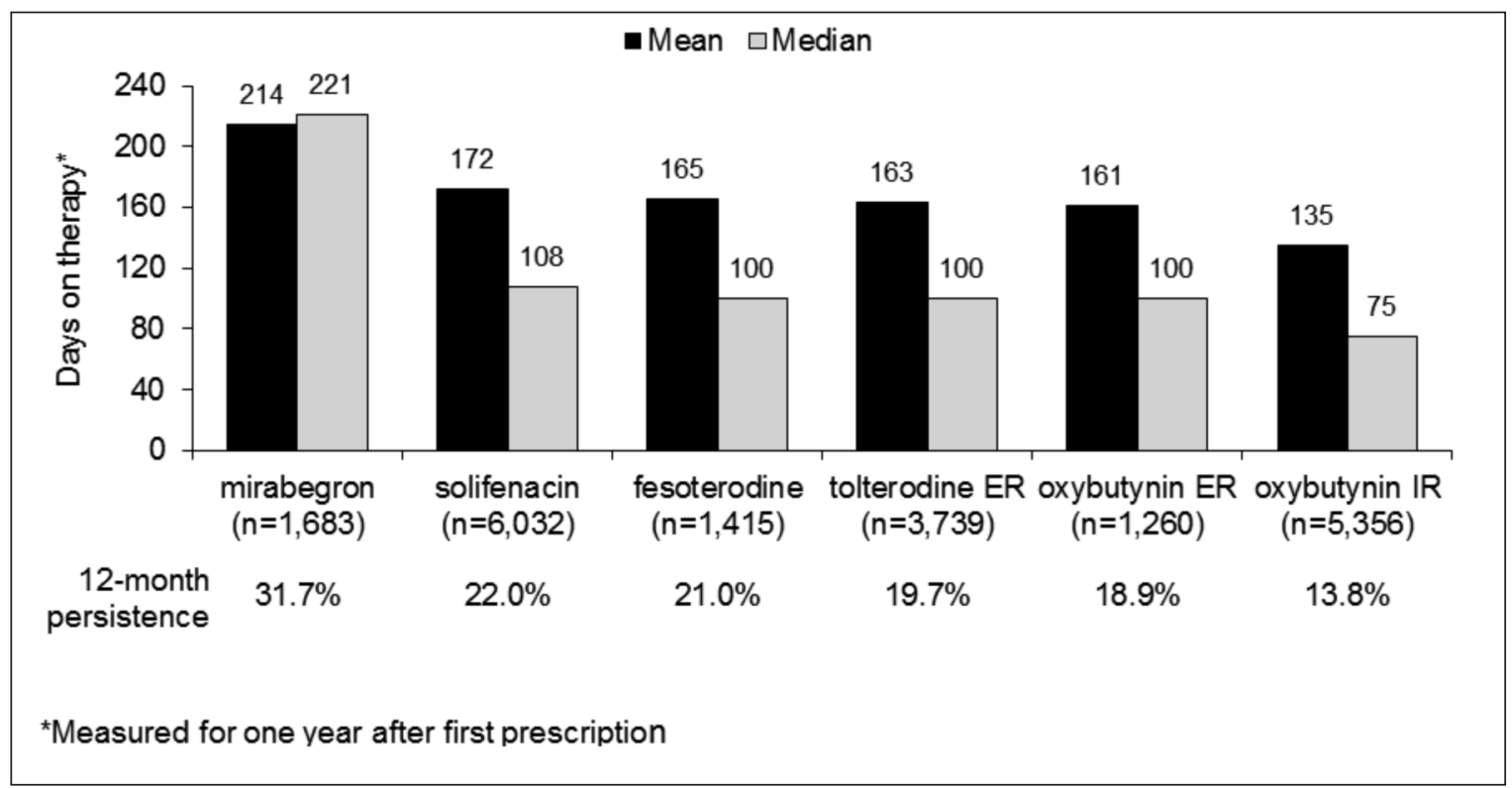

Fig. 3. Mean and median days on therapy, and persistence at 12 months, for the total population ( $n=19485)$. 


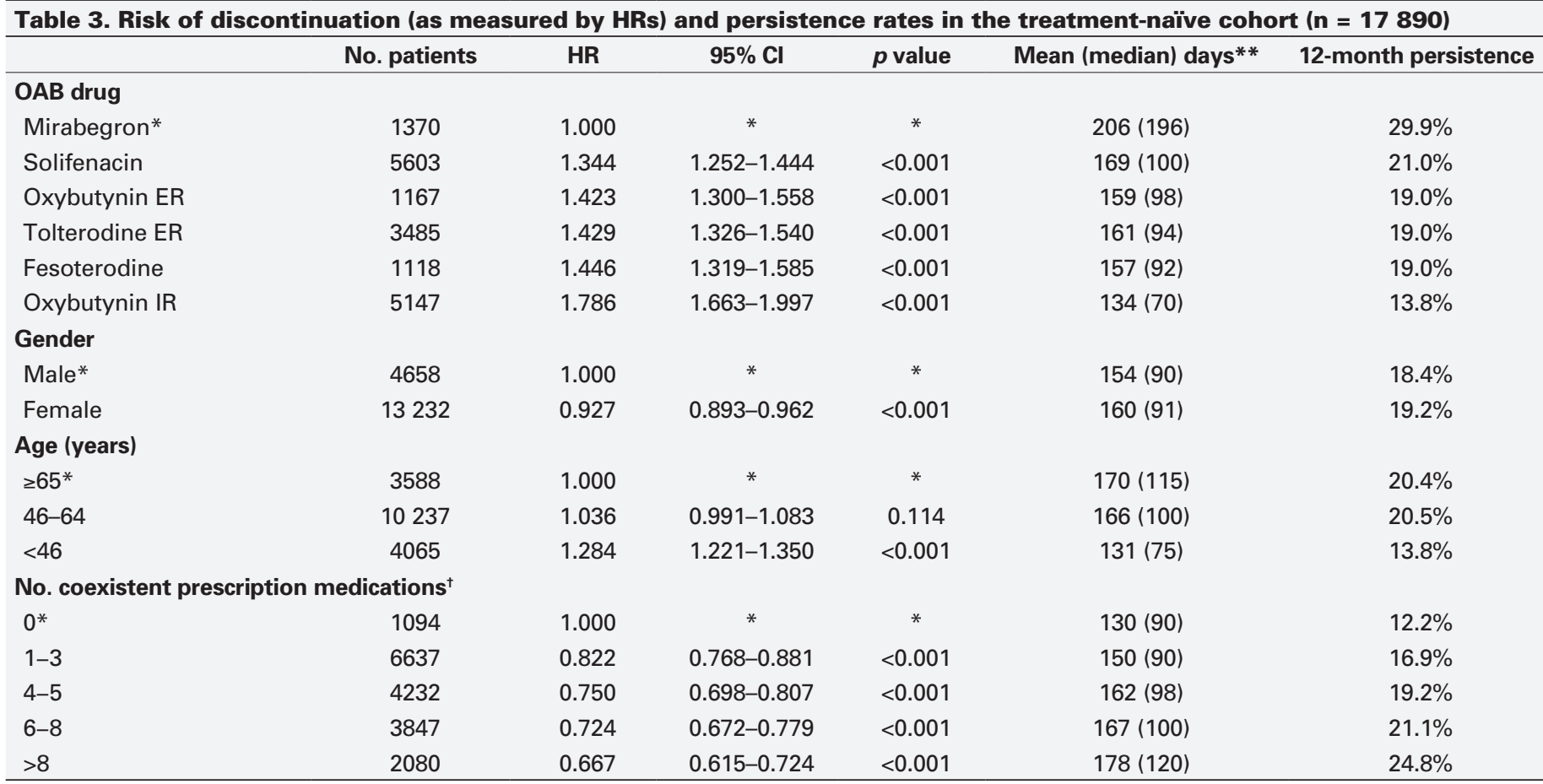

Data from a single multivariate model (Cox proportional hazards model). *Reference variable; †Fitted as a class variable; HR: hazard ratio; Cl: confidence interval; OAB: overactive bladder; IR: immediate release; ER: extended release. ${ }^{* *}$ Measured for one year after first prescription.

ation rates between patients aged 46 to 64 years and those aged $\geq 65$ years (Table 3 ). The greater the number of concurrent medications, the greater was the persistence with the OAB drug (Table 3).

\section{Persistence: Treatment-experienced cohort}

Mirabegron demonstrated greater persistence than antimuscarinics in treatment-experienced patients (Table 4, Fig. 5).

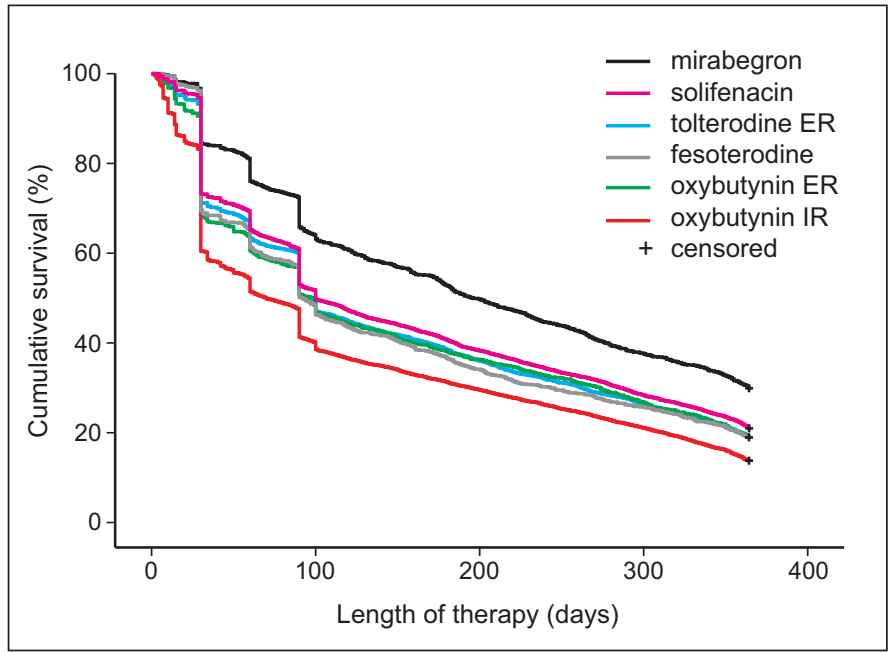

Fig. 4. Kaplan-Meier estimated rates of persistence with different $O A B$ drugs in treatment-naïve patients $(n=17890)$.
Patients taking oxybutynin IR had the lowest levels of persistence, and were about 2.2-times more likely to discontinue therapy relative to patients on mirabegron. As was seen with the treatment-naïve cohort, the greater the number of concurrent medications, the better the persistence with the $O A B$ drug. Other covariate groups in the treatment-experienced cohort (age and gender) were not included in the reduced model due to non-significance.

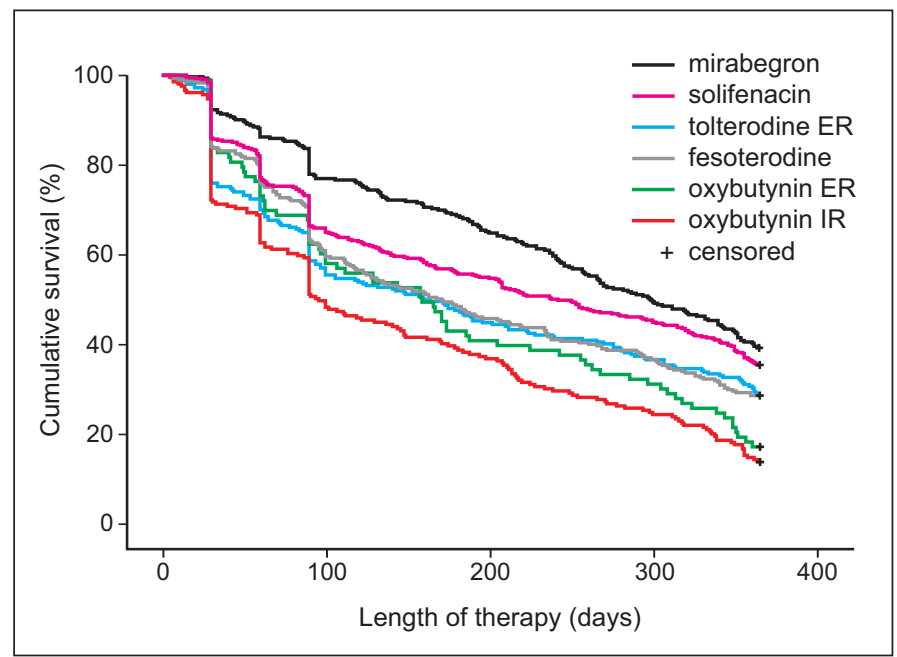

Fig. 5. Kaplan-Meier estimated rates of persistence with different $O A B$ drugs over time in the treatment-experienced patients $(n=1595)$. 
Wagg et al.

\begin{tabular}{|c|c|c|c|c|c|c|}
\hline & No. patients & HR & $95 \% \mathrm{Cl}$ & $p$ value & Mean (median) days** & 12-month persistence \\
\hline \multicolumn{7}{|l|}{ OAB drug } \\
\hline Mirabegron* & 313 & 1.000 & * & * & 249 (299) & $39.3 \%$ \\
\hline Solifenacin & 429 & 1.220 & $1.013-1.469$ & 0.037 & $220(242)$ & $35.4 \%$ \\
\hline Fesoterodine & 297 & 1.456 & $1.196-1.772$ & $<0.001$ & $197(171)$ & $28.6 \%$ \\
\hline Tolterodine ER & 254 & 1.532 & $1.248-1.881$ & $<0.001$ & $192(162)$ & $28.7 \%$ \\
\hline \multicolumn{7}{|c|}{ No. coexistent prescription medications ${ }^{\dagger}$} \\
\hline $0^{*}$ & 63 & 1.000 & * & * & $154(90)$ & $15.9 \%$ \\
\hline $1-3$ & 498 & 0.819 & $0.765-0.875$ & 0.038 & $196(365)$ & $24.9 \%$ \\
\hline $4-5$ & 397 & 0.744 & $0.693-0.798$ & 0.002 & 205 (177) & $33.0 \%$ \\
\hline $6-8$ & 379 & 0.715 & $0.665-0.768$ & $<0.001$ & $220(235)$ & $35.4 \%$ \\
\hline
\end{tabular}

Data from a single multivariate model (Cox proportional hazards model). *Reference variable; †Fitted as a class variable; Cl: confidence interval; OAB: overactive bladder; IR: immediate release ER: extended release. ${ }^{* *}$ Measured for one year after first prescription.

\section{Adherence}

Patients taking mirabegron demonstrated statistically significantly greater adherence than those taking antimuscarinics $(64.5 \%$ vs. $18.6 \%-49.2 \%$ for the different antimuscarinics, $p<0.001$ in pairwise comparisons between mirabegron and each antimuscarinic) (Fig. 6). Adherence was significantly greater in treatment-experienced than in treatment-naïve patients, and those under 46 years of age were the least adherent age category (Fig. 6). There was no significant difference in adherence between men and women (median MPR: $32.8 \%$ male vs. $32.8 \%$ female; $p=0.423$ ).

\section{Discussion}

Antimuscarinics are the principal pharmacological treatment for $\mathrm{OAB}$, but frequently give rise to anticholinergic side effects, ${ }^{21}$ which may be a factor in the high rate of discontinuation from these drugs. ${ }^{12}$ There are, therefore, many $\mathrm{OAB}$ sufferers whose symptoms may be amenable to control by alternative drugs, thus obviating the need to escalate treatment to, for example, neuromodulation or botulinum toxin therapy.

In this study, there was a tendency for discontinuation rates to be higher in men than in women, in younger patients (those under 46 years), and in those taking fewer concomitant medications. Younger age as a risk factor for discontinuation has also been reported elsewhere, ${ }^{11,12}$ though this may be a confounder as younger patients generally tend to take fewer prescription medications.

In the total study population, mirabegron was associated with greater persistence and more days on therapy compared with antimuscarinics at 12 months. This was also the case when considering subgroups of treatment-naïve and treatment-experienced patients. Mirabegron also demonstrated significantly greater adherence than antimuscarin- ics. Oxybutynin IR was the worst performing antimuscarinic in terms of persistence at 12 months, days on therapy, and adherence.

A lower incidence of anticholinergic adverse events with mirabegron seen in clinical trials may explain the improved persistence and adherence rates compared with antimuscarinic drugs. However, the persistence rate of $31.7 \%$ with mirabegron at 12 months in this study still means that about two-thirds of patients discontinued treatment, with a similar gradient of decline in persistence over time to that seen with antimuscarinics. It seems likely that discontinuation is affected by many factors in addition to anticholinergic adverse events, such as unmet expectations of treatment, recognition by patients of the chronic nature of their symptoms and the need for long-term treatment. Moreover, perhaps patients starting mirabegron as a recently introduced drug are often perceived as "severe" or "difficult to treat." If there is incomplete satisfaction with the efficacy of initial $\mathrm{OAB}$ treatment, consideration should be given to careful individual dose titration, offering higher doses if initial doses are well-tolerated, or switching medications. The latter may be a particularly worthwhile option for patients receiving oxybutynin IR, which is mandated as first-line therapy in many countries, but which was associated with the lowest persistence rates.

\section{Study limitations}

This study reflects early experience with mirabegron in Canada (first-year post-approval) and it is possible that persistence and adherence rates may vary as more prescribing experience is gained. Patients classified as treatment-naïve should be regarded as relatively naïve, as they might have received $\mathrm{OAB}$ medication before the 6-month look-back period. There were no data comparing prescriptions written by specialists versus those in primary care (specialists might 


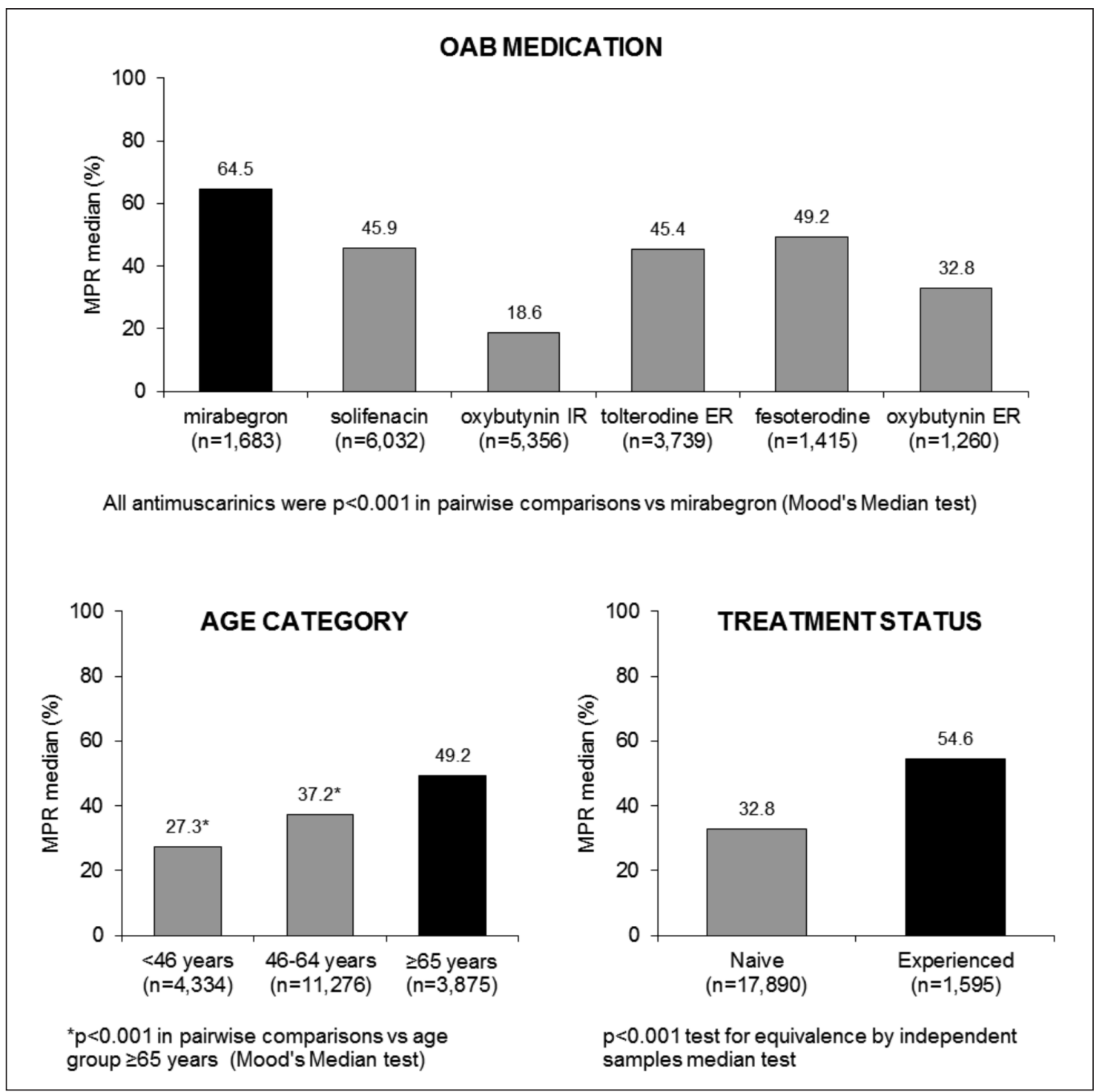

Fig. 6. Adherence (median Medication Possession Ratio) according to OAB medication, age category and treatment status (the reference comparator is shown as a black column in each case).

be early adopters of new drugs). It was not possible to relate persistence with therapy to symptom severity, and should be borne in mind that compared with most of the other target therapies a high proportion of mirabegron patients were male, aged $\geq 65$ years, and treatment-experienced, somewhat different from the average OAB patient. No data were available on detailed patient characteristics or different dosages of each target drug.

It is not known how data from this Canadian private prescription database equates to public prescriptions or prescribing practices in other countries. Solifenacin was the most widely prescribed antimuscarinic, perhaps reflecting the fact that prescribing for the private population in Canada is unconstrained by provincial policy regarding the first-line use of oxybutynin IR. Finally, it was not possible to deter- mine if any patients were potentially receiving drugs from the provincial health service, as well as via their private drug plan.

\section{Conclusion}

Improved persistence with treatment is an important goal in the development of new drugs for $\mathrm{OAB}$ and urinary incontinence. Mirabegron, at least in its early use, is associated with higher levels of persistence with therapy than the antimuscarinic drugs.

Acknowledgements: This study was funded by Astellas Pharma Canada, Inc. Editorial assistance was provided by Steven Sharpe PhD of SharpeCom Ltd (Midhurst, West Sussex, UK), and was funded by Astellas Pharma Canada Inc. Retrospective prescription claims data and statistical analyses were 
Wagg et al.

provided by IMS Brogan (IMS Health Canada Inc., Kirkland, Quebec, Canada). Team members: Kristen Reidel (Statistician), Brad Millson (Engagement Manager), Yvonne Zhang (Consultant). The statements, findings, conclusions, views, and opinions contained and expressed in this article are based in part on data obtained under license from the following IMS Brogan information service(s): Mirabegron Early Experience Studies, Data Period 2012-2014. All Rights Reserved. The statements, findings, conclusions, views, and opinions contained and expressed herein are not necessarily those of IMS Brogan or any of its affiliated or subsidiary entities.

Competing interests: Dr. Waggs has received funds from Astellas, Pfizer and SCA for consultancy. Dr. Franks is an employee of Astellas Pharma, Dr. Ramos is an employee of Astellas Pharma Canada. Dr. Berner is a former employee of Astellas Pharma.

This paper has been peer-reviewed.

\section{References}

1. Irwin DE, Milsom I, Hunskaar S, et al. Population-based survey of urinary incontinence, overactive bladder, and other lower urinary tract symptoms in five countries: Results of the EPIC study. Eur Urol 2006;50:130615. http://dx.doi.org/10.1016/i.eururo.2006.09.019

2. Stewart WF, Van Rooyen JB, Cundiff GW, et al. Prevalence and burden of overactive bladder in the United States. World J Urol 2003;20:327-36.

3. Abrams $P$, Cardozo L, Fall $M$, et al. The standardisation of terminology of lower urinary tract function: Report from the Standardisation Sub-committee of the International Continence Society. Neurourol Urodyn 2002;21:167-78. http://dx.doi.org/10.1002/nau.10052

4. Brown JS, McGhan WF, Chokroverty S. Comorbidities associated with overactive bladder. Am J Manag Care 2000;6:S574-9.

5. Wagner TH, Hu TW, Bentkover J, et al. Health-related consequences of overactive bladder. Am J Manag Care 2002;8:S598-607.

6. Abrams P, Kelleher CJ, Kerr LA, et al. Overactive bladder significantly affects quality of life. Am I Manag Care 2000;6:S580-90.

7. Gomes T, Juurlink DN, Mamdani MM. Comparative adherence to oxybutynin or tolterodine among older patients. Eur J Clin Pharmacol 2012;68:97-9. http://dx.doi.org/10.1007/s00228-01 1-1090-8

8. Mauseth SA, Skurtveit S, Spigset 0 . Adherence, persistence and switch rates for anticholinergic drugs used for overactive bladder in women: Data from the Norwegian Prescription Database. Acta Obstet Gynecol Scand 2013;92:1208-15. http://dx.doi.org/10.1111/aogs.12196
9. Sexton CC, Notte SM, Maroulis C, et al. Persistence and adherence in the treatment of overactive bladder syndrome with anticholinergic therapy: A systematic review of the literature. Int J Clin Pract 201 1;65:56785. http://dx.doi.org/10.1111//.1742-1241.2010.02626.x

10. Sicras-Mainar A, Rejas J, Navarro-Artieda R, et al. Antimuscarinic persistence patterns in newly treated patients with overactive bladder: A retrospective comparative analysis. Int Urogynecol J 2014;25:485-92. http://dx.doi.org/10.1007/s00192-013-2250-4

11. Veenboer PW, Bosch JL. Long-term adherence to antimuscarinic therapy in everyday practice: A systematic review. J Urol 2014;191:1003-8. http://dx.doi.org/10.1016/i.juro.2013.10.046

12. Wagg A, Compion G, Fahey A, et al. Persistence with prescribed antimuscarinic therapy for overactive bladder: A UK experience. BJU Int 2012;110:1767-74. http://dx.doi.org/10.1111/i.1464410X.2012.11023.x

13. Linner L, Schioler H, Samuelsson E, et al. Low persistence of anticholinergic drug use in Sweden. Eur J Clin Pharmacol 201 1;67:535-6. http://dx.doi.org/10.1007/s00228-010-0917-z

14. Wagg A, Diles D, Berner T. Treatment patterns for patients on overactive bladder therapy: A retrospective statistical analysis using Canadian claims data. JHEOR 2015;3:43-55.

15. Herschorn S, Stothers L, Carlson K, et al. Tolerability of $5 \mathrm{mg}$ solifenacin once daily versus $5 \mathrm{mg}$ oxybutynin immediate release 3 times daily: Results of the VECTOR trial. J Urol 2010;183:1892-8. hittp://dx.doi. org/10.1016/i.juro.2010.01.012

16. Kumar V, Templeman L, Chapple CR, et al. Recent developments in the management of detrusor overactivity. Curr Opin Urol 2003;13:285-91. http://dx.doi.org/10.1097/00042307-200307000-00004

17. Yamaguchi 0. Beta3-adrenoceptors in human detrusor muscle. Urology 2002;59:25-9. http://dx.doi. org/10.1016/S0090-4295(01)01635-1

18. Maman K, Aballea S, Nazir J, et al. Comparative efficacy and safety of medical treatments for the management of overactive bladder: A systematic literature review and mixed treatment comparison. Eur Urol 2014;65:755-65. http://dx.doi.org/10.1016/i.eururo.2013.11.010

19. Chapple CR, Kaplan SA, Mitcheson D, et al. Randomized double-blind, active-controlled phase 3 study to assess 12-month safeety and efficacy of mirabegron, a beta(3)-adrenoceptor agonist, in overactive bladder. Eur Urol 2013;63:296-305. http://dx.doi.org/10.1016/i.eururo.2012.10.048

20. Wagg A, Cardozo L, Nitti VW, et al. The efficacy and tolerability of the beta3-adrenoceptor agonist mirabegron for the treatment of symptoms of overactive bladder in older patients. Age Ageing 2014;43:666-75. http://dx.doi.org/10.1093/ageing/afu017

21. Chapple CR, Khullar V, Gabriel Z, et al. The effects of antimuscarinic treatments in overactive bladder: An update of a systematic review and meta-analysis. Eur Urol 2008:54:543-62. http://dx.doi. org/10.1016/j.eururo.2008.06.047

Correspondence: Dr. Adrian Wagg, Department of Medicine, University of Alberta, AB; adrian.wagg@ualberta.ca 